\title{
Modeling Plant Population and Rectangularity Effects on Broccoli Head Weights and Yield
}

\author{
M.P. Westcott and N.W. Callan \\ Western Agricultural Research Center, Montana Agricultural Experiment Station, Montana State \\ University, 580 Quast Lane, Corvallis, MT 59828
}

Additional index words. clumping, exponential model, nitrogen, reciprocal model, Brassica oleracea

\begin{abstract}
Broccoli (Brassica oleracea L. var. italica) head weights and yields are highly sensitive to plant densities (P) and rectangularity. Broccoli cultivars were grown at four plant spacings $\left(2.2\right.$ to $\left.8.6 \mathrm{plants} / \mathrm{m}^{2}\right)$ and four $\mathrm{N}$ rates (O to $336 \mathrm{~kg} \mathrm{~N} / \mathrm{ha}$ ) in 1986 and 1987. In 1988, plug spacings, as above, were factorially combined with treatments of one, two, or three plants per plug. Head weight $(w)$ data were fitted to the reciprocal model: $1 / w=a+b p$ and the exponential model: $w=A K^{\mathrm{p}}$, where $\mathbf{a}, \mathrm{b}, \mathrm{A}$, and $\mathrm{K}$ are constants. Nitrogen rate did not interact with $\mathbf{p}$. In 1986 and 1987, both the reciprocal and exponential models fit the $w$ data (expressed as $w$ relative to $w_{\text {max }}$ for each cultivar) with highly significant $R^{2}$ values of 0.525 to 0.605 . Yield equations derived from these models were asymptotic. In 1988, clumping (multiple plants per plug) reduced head weights but interacted with plant density. Only the exponential model could account for the assumption that clumping effects diminish as plant densities increase; the reciprocal model predicted the opposite effect. The exponential model was expanded to the form: $\mathbf{w}=\mathrm{CAK}^{\mathrm{p}}$, where $\mathrm{C}$ is proportionate reduction of $w$ due to clumping. Derived yield models were asymptotic for the reciprocal model and parabolic for the exponential model.
\end{abstract}

Individual broccoli plants have essentially only one yield component of commercial importance-head size, or harvested portion of the main stem, including the immature inflorescence. When yield is expressed on an area basis, an additional component of yield is the plant population density, which has considerable influence on the size and weigh $\backslash$ of individual heads. While crop species such as cereals have several yield components whose compensation can render total yield relatively insensitive to plant population densities over ranges near optimum, broccoli yields are highly dependent on plant spacings and continue to show increases at densities that render head weights so small as to be unmarketable (Chung, 1982; Cutcliffe, 1975; Dufault and Waters, 1985). Manipulation of plant densities is, perhaps, the most effective method of controlling both yield and quality of this vegetable.

The objective of studying the effects of population densities on broccoli head weights and yield for certain environments is to define the highest population density that will ensure head weights of a marketable size, thus ensuring maximum marketable yield. Results from such studies, conducted for local application, become more widely adapted if they can be fitted to predictive models. Such models take several forms (Wiley and Heath, 1969). The most common models relate individual plant yield to population density through a reciprocal equation, such as that proposed by Holliday (1960):

$$
1 / \mathrm{w}=\mathrm{a}+\mathrm{bp},
$$

where $\mathrm{w}$ is individual plant weight or yield, $\mathrm{p}$ is plant density, and $\mathrm{a}$ and $\mathrm{b}$ are constants. This linear form of the equation describes an asymptotic response of area yield to plant density, whereas expansion to a quadratic equation describes a parabolic response. Biological meaning is ascribed to the parameters: $1 / \mathrm{a}$ is the plant yield at low density representing genetic potential and $1 / b$ is the area yield at high density representing environmental potential. These attributes of the reciprocal form were cited as reasons for preference by Wiley and Heath (1969).

Received for publication 5 Feb. 1990. Montana Agricultural Experiment Station Journal Series no. J-2453. The cost of publishing this paper was defrayed in part by the payment of page charges. Under postal regulations, this paper therefore must be hereby marked advertisement solely to indicate this fact.
Chung $(1982,1985)$ used the reciprocal model to describe broccoli yield responses to plant density, while other workers have largely ignored such analysis for broccoli.

Exponential equations (Cramer and Jackobs, 1965; Duncan, 1958) are of the form:

$$
\mathrm{W}=\mathrm{A} \mathrm{K}^{\mathrm{P}}
$$

or linearized by $1 \mathrm{n}$ transformation to:

$$
\ln \mathrm{w}=\ln \mathrm{A}+\mathrm{pln} \mathrm{K} \text {, }
$$

where $\mathrm{A}$ and $\mathrm{K}$ are constants, $\mathrm{A}$ being equivalent to $1 / \mathrm{a}$ in Eq. [1] and $\mathrm{K}$ a competition coefficient. This equation describes a parabolic area yield response to plant density, with a yield optimum occurring at a density of $-1 / \operatorname{lnK}$. This optimum is of little practical value for a crop such as broccoli due to quality considerations and may be why the exponential form has not been applied to broccoli.

The above equations do not specifically account for planting pattern and are best suited for conditions where rectangularity is a dependent function of plant density. Duncan (1984) considered that a crowding factor is more valuable than plant density per se in the exponential equation for corn ( Zea mays L.):

$$
\mathrm{w}=\mathrm{w}_{0} \mathrm{e}^{\mathrm{EC}},
$$

where $\mathrm{w}_{0}$. is plant yield at zero crowding, $\mathrm{E}$ is the constant fraction of yield reduction due to crowding, and $\mathrm{C}$ is crowding. The value of $\mathrm{C}$ can be estimated from experimental data. Sutherland and Benjamin (1987) developed an integrative model based on the geometry of space available per plant, but the number of assumptions involved and the necessity for estimating the parameters of the equation limit the immediate applicability of their approach. Studies on direct effects of planting patterns on broccoli yield (Lancaster et al., 1985; Palevitch, 1970) have not fitted the data to mathematical description.

Plant rectangularity has practical consideration. Mechanical planting of broccoli places constraints on both inter- and intrarow spacings. One method of manipulating densities that has received little attention is the seeding of more than one plant per plug in planting trays, thus increasing the number of plants per unit area without increasing the number of plugs set out. 
This might make certain types of equipment more adapted to planting high densities and speed planting.

Another consideration is the interaction between plant densities and other management practices, such as fertilization, that also affect head size and yield (Cutcliffe, 1971; Dufault and Waters, 1985; Kowalenko and Hall, 1987; Letey et al., 1983). The interaction between $\mathrm{N}$ fertilization and plant density has not been analyzed statistically.

The objective of this research was to investigate the response of broccoli head weight and area yield to plant population density, level of $\mathrm{N}$, and plant rectangularity. This goal was pursued through a progression of field experiments defining, first, the simple effects of plant density and interaction with $\mathrm{N}$ fertilization and, second, the compounding effects of planting pattern with density.

\section{Materials and Methods}

The field experiments described here were conducted at the Western Agricultural Research Center, Montana Agricultural Experiment Station, located in the Bitterroot Valley of western Montana. The soil is a Burntfork loam, a mixed typic Argiborall. One experiment was conducted during each of the 3 years, 1986 through 1988. Transplanting dates for 6-week-old plants were between 19 May and 4 June each year. Experimental areas were treated with $\quad \alpha, \alpha, \alpha-1 \quad$ trifluoro-2,6 -dinitro-N, N-dipropyl-ptoluidine (trifluralin) at $0.6 \mathrm{~kg}$ a.i./ha preplant, incorporated for weed control, and fertilized uniformly with $23 \mathrm{~kg} \mathrm{P} / \mathrm{ha}$ and 56 $\mathrm{kg} \mathrm{K} / \mathrm{ha}$. Irrigation was by sprinkler. Insect control was achieved with applications of O; O-diethyl O- [6-methyl-2-( 1-methylethyl)-4-pyrimidinyl] phosphorothioate (diazinon), as needed. Nitrogen fertility was a variable for the first two experiments, but was applied uniformly to the third in three applications of 84 $\mathrm{kg} \mathrm{N} / \mathrm{ha}$ each. Row spacing was held constant at $76 \mathrm{~cm}$ throughout .

In 1986, treatments consisted of the cultivars Green Duke, Green Valiant, and Defender; $\mathrm{N}$ as $\mathrm{NH}_{4} \mathrm{NO}_{3}$ at rates of 84,168 , 252 , and $336 \mathrm{~kg} \cdot \mathrm{ha}^{-1}$; and plant spacings of $15,30,45$, and 60 $\mathrm{cm}$ within the row. These spacings resulted in plant densities of $8.6,4.3,2.9$, and 2.2 plants $/ \mathrm{m}^{2}$, respectively. Nitrogen rate main plots were arranged in a randomized complete block with three replications. These main plots were split into subplots of plant spacing treatments and cultivars as sub-subplots. Sub-subplot size was a single row $3.7 \mathrm{~m}$ long. Nitrogen was applied at weekly intervals of $84 \mathrm{~kg} \cdot \mathrm{ha}^{-1}$ each beginning in early June untilthe specified rates had been achieved. The experiment in 1987 was identical to that in 1986, except that a fourth cultivar, Prominence, was added.

The 1988 experiment included the cultivars Prominence and Packman seeded and thinned in trays with one, two, or three plants per plug. These were transplanted to main plots of plug spacings of $15,30,45$, and $60 \mathrm{~cm}$ within the row arranged in a randomized complete block with four replications. Subplots were plants per plug (q, Table 1) and sub-subplots were cultivars. Plant densities achieved for $\mathrm{q}_{1}$ were 8.6, 4.3, 2.9, and 2.2 plants $/ \mathrm{m}^{2}$; for $\mathrm{q}_{2}, 17.2,8.6,5.7$, and $4.3 \mathrm{plants} / \mathrm{m}^{2}$; and for $\mathrm{q}_{3}, 25.8,12.9,8.6$, and 6.5 plants $/ \mathrm{m}^{2}$ for the respective spacings.

In each experiment, the top $15 \mathrm{~cm}$ of the inflorescence with stem from each plant was hand-harvested, leaves removed, and individually weighed as plants matured. The statistical program MSUSTAT (Lund, 1986) was used for analysis of variance procedures on head weight and yield data and for regression of head weights against plant densities fitted to the reciprocal and
Table 1. Definition and calculation of symbols used in modeling plant density and clumping effects on broccoli head weights.

\begin{tabular}{|c|c|c|}
\hline Symbol & Definition & Calculation \\
\hline A & $\begin{array}{l}\text { Coefficient of exponential } \\
\text { model, w as p approaches } 0\end{array}$ & By regression, $w_{\max }$ \\
\hline a & $\begin{array}{c}\text { Intercept of reciprocal model, } \\
1 / \mathrm{w} \text { as } \mathrm{p} \text { approaches } 0\end{array}$ & By regression, $\mathrm{w}_{\max }{ }^{-1}$ \\
\hline b & $\begin{array}{l}\text { Slope of reciprocal model, } \\
1 / \text { yield as p approaches max }\end{array}$ & By regression \\
\hline $\mathrm{C}$ & Coefficient of clumping & $\mathrm{w}_{\mathrm{x}} / \mathrm{w}_{1}$ \\
\hline $\mathrm{K}$ & $\begin{array}{l}\text { Coefficient of competition in } \\
\text { exponential model }\end{array}$ & $\begin{array}{l}\text { By regression, }-1 / \operatorname{lnK} \\
=\mathrm{P}_{\text {optimum }}\end{array}$ \\
\hline $\mathrm{p}$ & Plant density & plants $/ \mathrm{m}^{2}$ \\
\hline q & Plants per plug & plants/plug \\
\hline$q_{x}$ & $\mathrm{x}$ plants per plug & plants/plug \\
\hline w & Head weight & g/plant \\
\hline$w_{x}$ & $\begin{array}{l}\text { Head weight with } \mathrm{x} \text { plants per } \\
\text { plug }\end{array}$ & $\mathrm{g} / \mathrm{plant}$ \\
\hline
\end{tabular}

Table 2. Simple $\mathrm{N}$ rate effects on broccoli head weights and yield in 1986 and 1987. ${ }^{2}$

\begin{tabular}{cccccr}
\hline \multirow{2}{*}{$\begin{array}{c}\mathrm{N} \\
\left(\mathrm{kg} \cdot \mathrm{ha}^{-1}\right)\end{array}$} & \multicolumn{2}{c}{ Head wt $(\mathrm{g})$} & & \multicolumn{2}{c}{ Yield $\left(\mathrm{kg} \cdot \mathrm{ha}^{-1}\right)$} \\
\cline { 2 - 4 } \cline { 5 - 6 } & 1986 & 1987 & & 1986 & 1987 \\
\hline 84 & 157 & 200 & 6029 & 8047 \\
168 & 162 & 212 & 6467 & 8480 \\
252 & 187 & 227 & 7141 & 8888 \\
336 & 188 & 223 & 7344 & 9222 \\
$\mathrm{LSD}_{0.05}$ & 15 & 17 & 714 & 683 \\
\hline \hline
\end{tabular}

'The interaction of $\mathrm{N}$ rate and plant density was not significant.

exponential equations presented above (Eq. [1] and [2]). All regressions were performed with individual replication values. Symbols used in the modeling are presented in Table 1.

\section{Results and Discussion}

Significant responses to $\mathrm{N}$ application rates were evidenced for both head weights and area yields in 1986 and 1987 (Table 2). No statistical interactions between $N$ rate and plant density were noted for either of these variables. This result justified separate analyses of plant density and $\mathrm{N}$ rate effects and simplified the design for the 1988 experiment, where a single $\mathrm{N}$ rate was used.

Plant density and cultivar effects on head weights for 1986 and 1987 are summarized in Table 3. The 1986 environment was particularly restrictive to growth for 'Green Valiant' and 'Green Duke' and a significant cultivar x plant density interaction occurred. The interaction is explained by significant differences between head weights for 'Defender' and 'Green Valiant' at all but highest plant density. The 1987 site was more uniformly conducive to growth for all cultivars; significant differences in performance among cultivars persisted but without the wide disparities and interactions of 1986.

The head weight data were fitted to the reciprocal and exponential equations (Eq. [1] and [2], Fig. 1). Absolute head weight values for 1986 gave poor fit, with $R^{2}$ values of 0.337 and 0.318 for Eq. [1] and [2], respectively. This poor fit was due to wide differences in values among cultivars. The data were, therefore, expressed as relative head weights, calculated as the ratio between head weight for each cultivar at a given plant density and that at the lowest plant density (2.2 plants/ $\mathrm{m}^{2}$ ). This transformation isolated plant density effects and improved $R^{2}$ values considerably (Fig. 1). The $R^{*}$ values for 
Table 3. Plant density (p) and cultivar (cv) effects on broccoli head weights (in grams) in 1986 and 1987.

\begin{tabular}{|c|c|c|c|c|}
\hline \multirow[b]{2}{*}{ Cultivar } & \multicolumn{4}{|c|}{ Plant density (plants $/ \mathrm{m}^{2}$ ) } \\
\hline & 2.2 & 2.9 & 4.3 & 8.6 \\
\hline & \multicolumn{4}{|c|}{1986} \\
\hline Defender & 348 & 296 & 221 & 152 \\
\hline Green Valiant & 184 & 166 & 148 & 111 \\
\hline Green Duke & 149 & 132 & 103 & 73 \\
\hline Mean & 227 & 198 & 157 & 112 \\
\hline $\mathrm{LSD}_{0.05} \mathrm{p}$ & \multicolumn{4}{|c|}{15} \\
\hline $\operatorname{LSD}_{0.05} \mathrm{CV}$ & \multicolumn{4}{|c|}{13} \\
\hline \multirow[t]{2}{*}{$\mathrm{LSD}_{0.05} \mathrm{p} \times \mathrm{CV}$} & \multicolumn{4}{|c|}{46} \\
\hline & \multicolumn{4}{|c|}{1987} \\
\hline Defender & 277 & 254 & 221 & 172 \\
\hline Green Valiant & 212 & 241 & 203 & 146 \\
\hline Green Duke & 246 & 225 & 193 & 133 \\
\hline Prominence & 262 & 293 & 215 & 156 \\
\hline Mean & 249 & 253 & 208 & 152 \\
\hline $\mathrm{LSD}_{0.05} \mathrm{p}$ & \multicolumn{4}{|c|}{17} \\
\hline $\mathrm{LSD}_{0.05} \mathrm{CV}$ & \multicolumn{4}{|c|}{17} \\
\hline $\mathrm{LSD}_{0.05} \mathrm{p} \times \mathrm{CV}$ & \multicolumn{4}{|c|}{ NS } \\
\hline
\end{tabular}

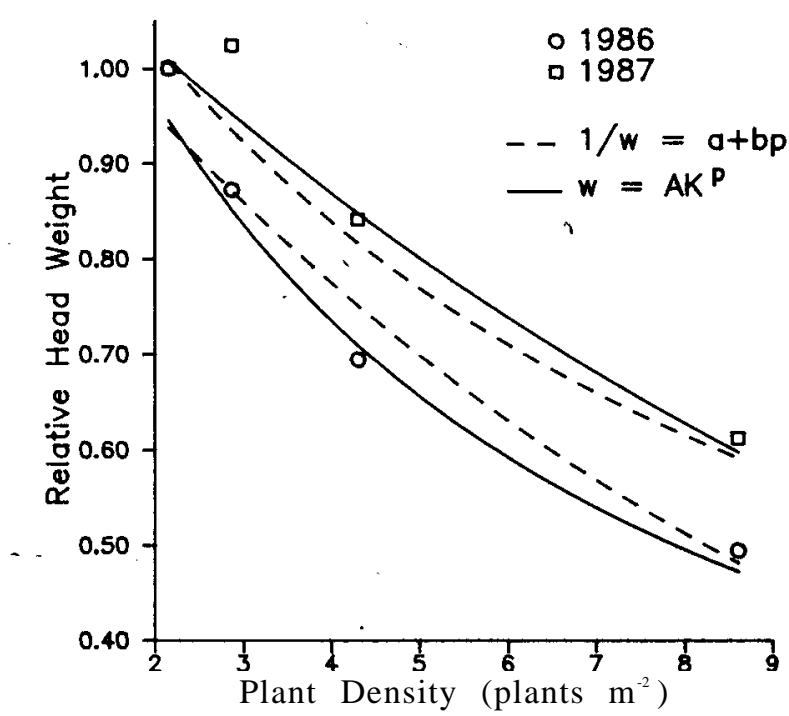

Fig. 1. Relative head weight (w) response of broccoli to plant density (p) in 1986 and 1987. Regressions fitted to the reciprocal and exponential models are: $1986,1 / \mathrm{w}=0.704+0.165 \mathrm{p}, R^{2}=0.571^{* *}$, and $\mathrm{w}=1.703\left(0.902^{\mathrm{P}}\right), \mathrm{R}^{2}=0.605^{* *} ; 1987, \mathrm{I} / \mathrm{w}=0.760+$ $0.108 \mathrm{p}, R^{2}=0.557$, and $\mathrm{w}=1.201\left(0.922^{\mathrm{p}}\right), R^{2}=0.525^{* *}$.

regression of absolute head weights from 1987 ( 0.577 and 0.523 for Eq. [1] and [2]) were not notably altered by the transformation due to more uniform performance among cultivars.

Both the reciprocal and exponential models appear to adequately describe the relationship between individual head weight and plant density. The exponential equation had a slightly higher $R^{2}$ value in 1986 but a slightly lower one in 1987, in comparison to the reciprocal equation. Values for $\mathrm{I} / \mathrm{a}$ in Eq. [1] and $\mathrm{A}$ in Eq. [2] were comparable and consistent among years.

Simple plant density effects on yield are presented in Table 4 , since no interaction with cultivars occurred for this variable. Significant effects are obvious and consistent from year to year. These data are expressed as relative yields in Fig. 2 (calculated as above for relative head weights, but with the highest plant density as the standard for each cultivar and year). The fitted lines in Fig. 2 were calculated as the regressions from Fig. 1
Table 4. Plant density effects on broccoli yields in 1986 and 1987.

\begin{tabular}{crr}
\hline \hline \multirow{2}{*}{$\begin{array}{c}\text { Plant density } \\
\text { (plants/m*) }\end{array}$} & \multicolumn{2}{c}{ Yield $\left(\mathrm{kg} \cdot \mathrm{ha}^{-1}\right)$} \\
\cline { 2 - 3 } 2.2 & 4886 & 1987 \\
2.9 & 5678 & 5357 \\
4.3 & 6778 & 7271 \\
8.6 & 9642 & 8953 \\
LSD $_{0.05}$ & 71 & 13050 \\
\hline
\end{tabular}

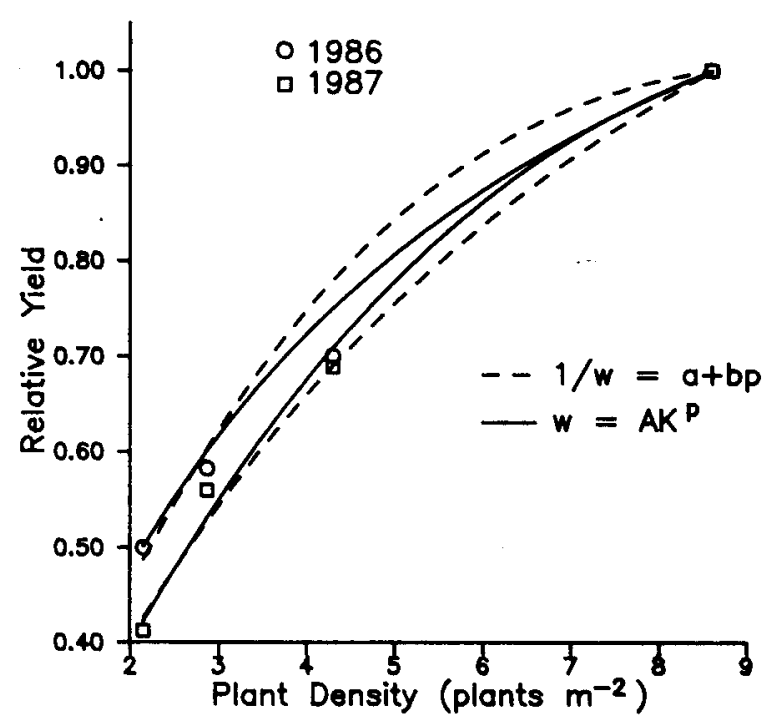

Fig. 2. Rëlative yield response of broccoli to plant density (p). Fitted lines are derived by multiplication of regressions in Fig. 1 by p.

multiplied by $\mathrm{p}$. These yield equations show asymptotic trends toward the highest levels of plant density.

Plant density effects on individual plant yield are complicated by the additional factor of plant rectangularity. Planting more than one broccoli plant per plug increases competition among plants, particularly at low densities, where competition is otherwise minimized. The combined effects of plant density and clumping on individual plant yield in 1988 are described by fitting separate lines for each level of q (Table 1) to the reciprocal and exponential models, respectively (Figs. 3 and 4). Both models describe the data well, although $R^{2}$ values for the reciprocal model with one or two plants per plug $\left(\mathrm{q}_{1}\right.$ and $\mathrm{q}_{2}$, respectively) are higher than for the exponential model. Clumping reduced head weights at equal plant densities.

Lines $\mathrm{q}_{1}, \mathrm{q}_{2}$, and $\mathrm{q}_{3}$ diverge slightly across the range of overlapping plant densities in the reciprocal model (Fig. 3), reflecting increasing values of $b$ with increasing values of $q$. Values for $\mathrm{K}$ (Table 1) in the exponential model also increase with increasing $\mathrm{q}$, but have opposite effects on the relationship among the lines across plant densities; lines $\mathrm{q}_{1}, \mathrm{q}_{2}$, and $\mathrm{q}_{3}$ converge in Fig. 4. These differences may at first appear subtle, but they have important meaning in considering the ability of each model to describe rectangularity effects on individual plant yields.

Equidistant plant spacing, at a density where plants at full growth are just touching, maximizes plant density with no interplant competition. If this plant density is held constant, but plants are clumped, then individual plant yield is reduced due to imposed interplant competition. The ratio between individual plant yields of clumped and nonclumped plants is a measure of the severity of the clumping effect at a given plant density. Define coefficient of clumping $\mathrm{C}$ as $\mathrm{w}_{\mathrm{x}} / \mathrm{w}_{1}$, where $\mathrm{x}=$ the 


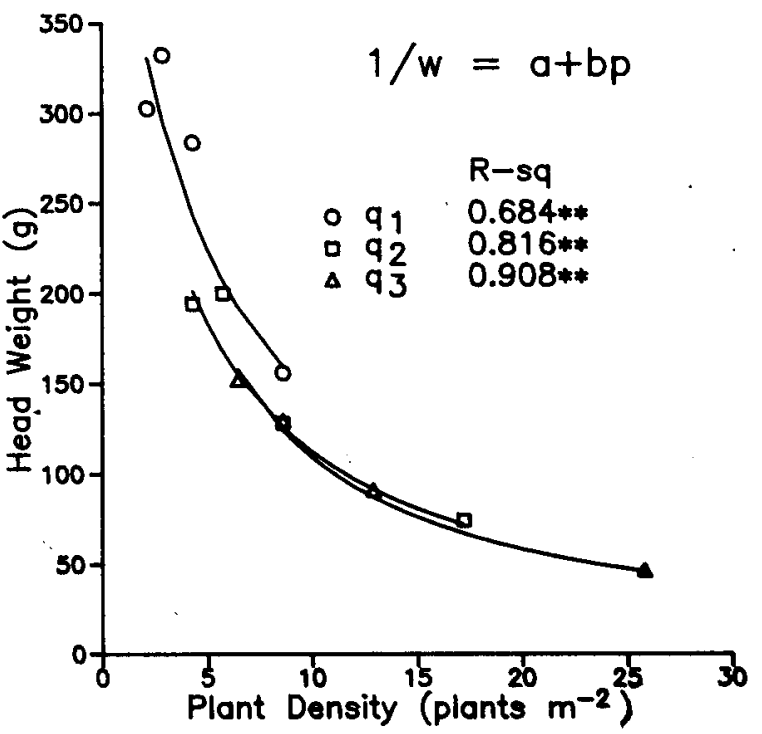

Fig. 3. Broccoli head weight (w) response to plant density (p) as affected by plants per plug (q). Regressions fitted to the reciprocal model are: for $\mathrm{q}_{1}, 1 / \mathrm{w}_{1}=1.94 \times 10^{3}+5.05 \times 10^{-4} \mathrm{p}$; for $\mathrm{q}_{2}$, $1 / \mathrm{w}_{2}=2.00 \times 10^{-3}+6.86 \times 10^{-4} \mathrm{p}$; and for $\mathrm{q}_{3}, 1 / \mathrm{w}_{3}=1.15 \times$ $10^{-3}+8.04 \times 10^{-4} \mathrm{p} . \mathrm{R}^{2}$ values are presented in the figure.

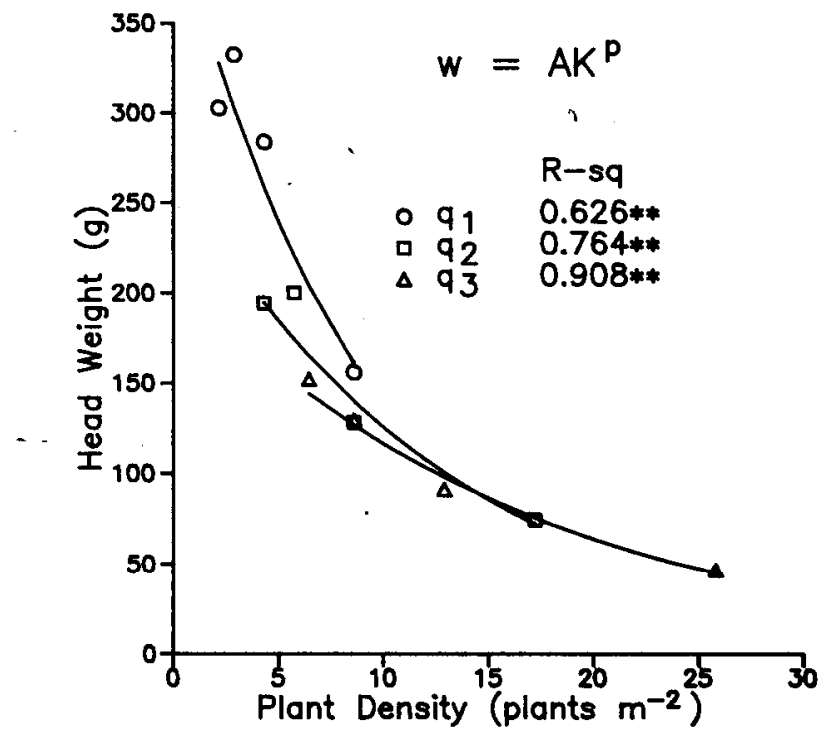

Fig. 4. Broccoli head weight (w) response to plant density (p) as affected by plants per plug (q). Regressions fitted to the exponential model are: for $\mathrm{q}_{1}, \mathrm{w}_{1}=415\left(0.895^{\mathrm{P}}\right)$; for $\mathrm{q}_{2}, \mathrm{w}_{2}=272\left(0.926^{\mathrm{P}}\right)$; and for $\mathrm{q}_{3}, \mathrm{w}_{3}=213\left(0.941^{\mathrm{P}}\right)$. $\mathrm{R}^{2}$ values are presented in the figure.

number of plants per plug (Table 1). Assuming no positive effect of clumping on head weight, $\mathrm{C}$ is less than or equal to one and the higher its value, the less severe the clumping effect.

Clumping effects are minimized at high densities since interplant competition is high, regardless of rectangularity. The value of $\mathrm{C}$, therefore, increases with increasing plant density, and clumping effects become less important as increasing plant density brings individual plants or clumps into closer proximity.

The fit of Eqs. [1] and [2] to the data predict contradicting effects of plant density on $\mathrm{C}$. For the reciprocal model, increases in $b$ with increases of $q$ mean that $C$ decreases with increasing plant density, opposite of our assumption. For the exponential model, however, increasing values of A (Table 1) with increasing values of $\mathrm{q}$ mean that $\mathrm{C}$ increases as plant density increases, consistent with our assumption. Further testing is needed to confirm whether the failure of the reciprocal model to adequately describe clumping interactions with plant density is an intrinsic property of the model or is an artifact unique to this data set.

The exponential model is adaptable to incorporation of $\mathrm{C}$ into a single equation describing plant yield response to plant density across clumping regimens. Values for $\mathrm{C}$ were generated for $\mathrm{w}_{2}$ and $\mathrm{w}_{3}$ across the range of overlap for the three lines, from 4 to 9 plants $/ \mathrm{m}^{2}$ (Fig. 4). These values were regressed against the factors $\mathrm{p}, \mathrm{q}, \mathrm{q}^{-1}$, and $\mathrm{pq}$ in a stepwise multiple regression. The best fit was obtained with the regression $\mathrm{C}=0.094+1.111$ $\mathrm{q}^{-1}+0.013 \mathrm{pq}, R^{2}=0.997^{*} *$, indicating that $\mathrm{C}$ is inversely correlated with $\mathrm{q}$ and positively correlated with $\mathrm{pq}$ interaction. Again, this result fits the above assumptions.

The exponential equation (Eq. [4]) can be expressed as

$$
\mathrm{w}=\mathrm{CAK}^{\mathrm{P}}
$$

which accounts for clumping effects on head weights by multiplication with $\mathrm{C}$. The resultant regression equation is $\mathrm{w} / \mathrm{C}=$ $392\left(0.904^{\mathrm{P}}\right), R^{2}=0.916^{* *}$, where $\mathrm{C}$ is calculated from the above regression and is assumed as unity where $q=1$. This is an empirical derivation specifically suited to the condition of equidistant vs. clumped spacing within the row, but it gives a good description of the results and has biological and/or physical meaning for each component.

The regression equations in Figs. 3 and 4 were used to generate the yield functions in Figs. 5 and 6 by multiplication with p. Differences between the models are again quite noticeable. Both models show the restrictions on yield imposed by plant clumping, but the reciprocal model predicts an asymptotic yield response to plant density, while the exponential equation predicts a parabolic response. The parabolic response does not appear justified within the range of plant densities tested, which is academic, since high plant densities resulted in head weights far below market acceptability. There is no practical reason to consider plant density ranges where the parabolic response is expressed.

Marketable yield is maximized at the highest plant density that assures marketable head size. Each model predicts the plant

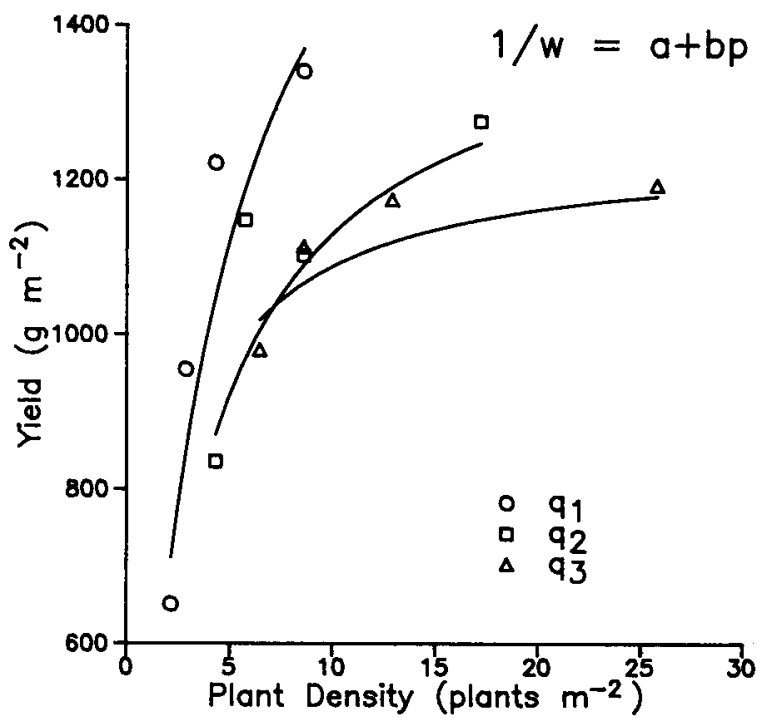

Fig. 5. Broccoli yield response to plant density (p) as affected by plants per plug. Lines fitted to the reciprocal model are derived by multiplication of regressions presented in Fig. 3 by p. 


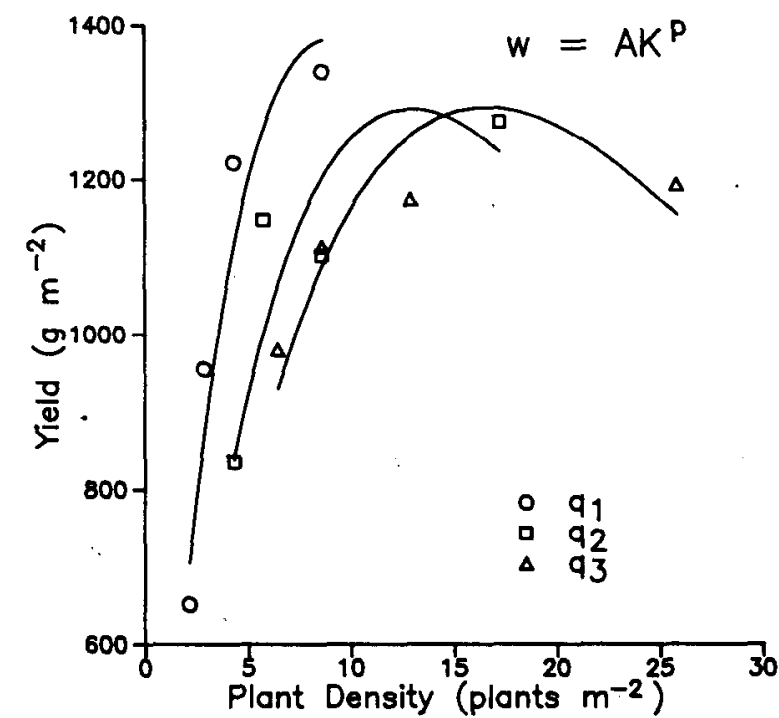

Fig. 6. Broccoli yield response to plant density (p) as affected by plants per plug. Lines fitted to the exponential model are derived by multiplication of recessions presented in Fig. 4 by p.

density required to achieve a specified head weight. This is simply a matter of inserting the desired value for $\mathrm{w}$ and solving for $\mathrm{p}$. However, the values for the "independent" variables in the equations are environment-specific. In this respect, values for $\mathrm{I} / \mathrm{a}$ in the reciprocal and $\mathrm{A}$ in the exponential equations should be regarded as the. genetic potential for the cultivar in the specific environment of experimentation. This problem can be partially overcome by expressing head weights as relative to maximum, which showed good agreement between 1986 and 1987 results. These equations may have application within a geographic region. Optimum plant spacings could be determined for specific sites based simply on knowledge of head weights for widely spaced plants for those sites.

Clumping was included as a factor to investigate broccoli head weight responses to very high densities and to test whether planting more than one plant per plug is a practical method for manipulating plant density. Clumping obviously imposes restrictions on head size development by an effect separate from plant density effects, although these factors interact; that is, clumping has less effect on head size as plant density increases. For most environments, however, clumping effects do not disappear until head size is below market acceptance. Therefore, attempts to increase plant densities for commercial production should give first consideration to single plants per plug.

Multiple plants per plug may have special application however. Mechanical transplanters have practical limits as to the number of plugs per unit length within the row and as to spacings between rows. As an example, if the transplanter were restricted to an intra-row spacing of $45 \mathrm{~cm}$, then two plants per plug would render higher yields than one plant per plug and maintain an average head weight $>200$ g (Figs. 3 and 5). Additionally, some environments are more productive than the environment we used and can sustain acceptable head sizes at higher plant densities. These more productive sites would more likely test the limits of mechanical transplanting. Also, multiple plants per plug should be considered where small head sizes are desirable or even tolerable below those achieved with the highest plant densities practiced with single plant per plug methods.

Final consideration should be given to the reduced cost of multiple vs. single plants per plug in achieving a given plant density. Multiple plants per plug require fewer trays and potting 'materials, less greenhouse space and maintenance before transplanting, less handling, and less planting time in comparison to the same number of plants in single arrangement. It is beyond the scope of this paper to give an economic analysis of these factors, but they will play a role in determining the acceptability of this technique for manipulating plant densities.

\section{Literature Cited}

Chung, B. 1982. Effects of plant density on the maturity and onceover harvest yields of broccoli. J. Hort. Sci. 57:365-372.

Chung, B. 1985. The effects of sowing time and plant density on the once-over harvest yields of broccoli. J. Hort. Sci. 60:57-64.

Cramer, S.G. and J.A. Jackobs. 1965. An exponential model for predicting optimum plant density and maximum corn yield. Agron. J. 57:241-244.

Cutcliffe, J.A. 1971. Effects of plant population, nitrogen, and harvest date on yield and maturity of single-harvested broccoli. HortScience 6:482-483.

Cutcliffe, J.A. 1975. Effects of plant spacing on single-harvest yields of several broccoli cultivars. HortScience 10:417-419.

Dufault, R.J. and L. Waters, Jr. 1985. Interaction of nitrogen fertility and plant populations on transplanted broccoli and cauliflower yields. HortScience 20:127-128.

Duncan, W.G. 1958. The relationship between corn populations and yield. Agron. J. 50:82-84.

Duncan, W.G. 1984. A theory to explain the relationship between corn population and grain yield. Crop Sci. 24:1141-1145.

Holliday, R. 1960. Plant population and crop yield. Nature (London) 186:22-24

Kowalenko, C.G. and J.W. Hall. 1987. Nitrogen recovery in singleand multiple-harvested direct-seeded broccoli trials. J. Amer. Sot. Hort. Sci. 112:4-8.

Lancaster, D. M., C.E. Johnson, and W.A. Young, 1985. Double-row cropping of broccoli for better yields. Louisiana Agr. 29:15-16.

Letey, J., W.M. Jarrell, N. Valoras, and R. Beverly. 1983. Fertilizer application and irrigation management of broccoli production and fertilizer use efficiency. Agron. J. 75:502-507.

Lund, R.E. 1986. MSUSTAT statistical analysis package. Res. Devel. Inst., Montana State Univ., Bozeman.

Palevitch, D. 1970. Effects of plant population and pattern on yield of broccoli (Brassica oleracea var. italica) in single harvest. HortScience 5:230-231.

Sutherland, R.A. and L.R. Benjamin. 1987. A new model relating crop yield and plant arrangement. Ann. Bot. 59:399-411.

Wiley, R.W. and S .B. Heath. 1969. The quantitative relationships between plant population and crop yield. Adv. Agron. 21:281-321. 